\title{
The Use of Fractal Features for Recognition of 3-D Discharge Patterns
}

\author{
A. Krivda, E. Gulski \\ High Voltage Laboratory, TU Delft, The Netherlands \\ L. Satish, ${ }^{1}$ and W. S. Zaengl \\ High Voltage Laboratory, ETH Zürich, Switzerland
}

\begin{abstract}
This work presents further results on the use of fractal features for recognition of 3-D partial discharge patterns. Two fractal features, the fractal dimension and lacunarity were calculated from 3-D discharge patterns and their power to discriminate among various discharge patterns was analyzed. The results indicate that fractal features possess fairly reasonable discriminating abilities.
\end{abstract}

\section{INTRODUCTION}

$\mathrm{T}$ ESTING of $\mathrm{HV}$ apparatus for partial discharges (PD) is a routine procedure for the assessment of insulation quality. Degradation effects of discharges on the insulation are well known and in many cases it is important to know their origin. For many years the discharges were observed on an oscilloscope screen $[1,2]$ and the interpretation of the ever changing discharge patterns was strongly dependent on the knowledge and experience of experts. Due to the increasing trend towards automation of PD measurement, in recent years the use of computeraided evaluation has become very popular. Different display techniques appeared to support the evaluation of PD measurements. The popularly used method is the 3-D representation of the relationship between the phase angle of discharge event, the discharge magnitude and the number of discharges, see Figure 1, where examples of such 3-D discharge patterns are shown. Each 3-D pattern was obtained by measuring discharges due to different defects. It can be seen that these patterns contain sufficient information for discharge discrimination and recognition. On the basis of these types of patterns, e.g., by using the mean pulse height, the pulse count distributions, etc., or the 3-D patterns themselves, a number of approaches and classification methods have gradually appeared for the automation of discharge recognition: expert systems [3, 4], identification functions [5], the hidden Markov models
[6], neural networks [7-10] statistical parameters [11-13], etc.

Recently, fractal features were employed for discharge recognition with encouraging results [14]. In this case only two parameters, the fractal dimension and lacunarity [15-18], calculated from 3-D PD patterns sufficiently discriminated among them. The calculation of the fractal features was, however, restricted to cavity patterns only. The aim of this work is to examine further the discriminating abilities of the fractal features when a wide variety of discharge patterns, such as corona discharges, surface discharges, cavity discharges, etc., have to be recognized. This and also recent work [14] will give a more complete picture about this new technique of PD recognition. Reasons for the use of fractal features and details of computing fractal dimension and lacunarity from 3-D PD patterns have already been published [14] and hence will not be repeated here.

\section{APPLICATION TO DISCHARGE PATTERNS}

PD patterns used in this work were measured with a conventional discharge detector (bandwidth 40 to 400 $\mathrm{kHz}$ ) extended with a statistical discharge analyzer (TEAS 570 by Haefely [19]). The analyzer divides one power frequency cycle of $50 \mathrm{~Hz}$ into a number of phase 


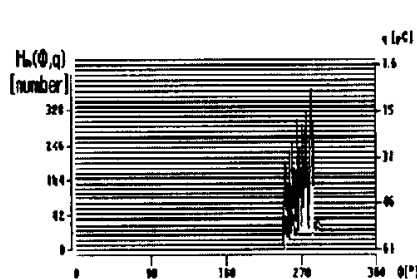

(a)
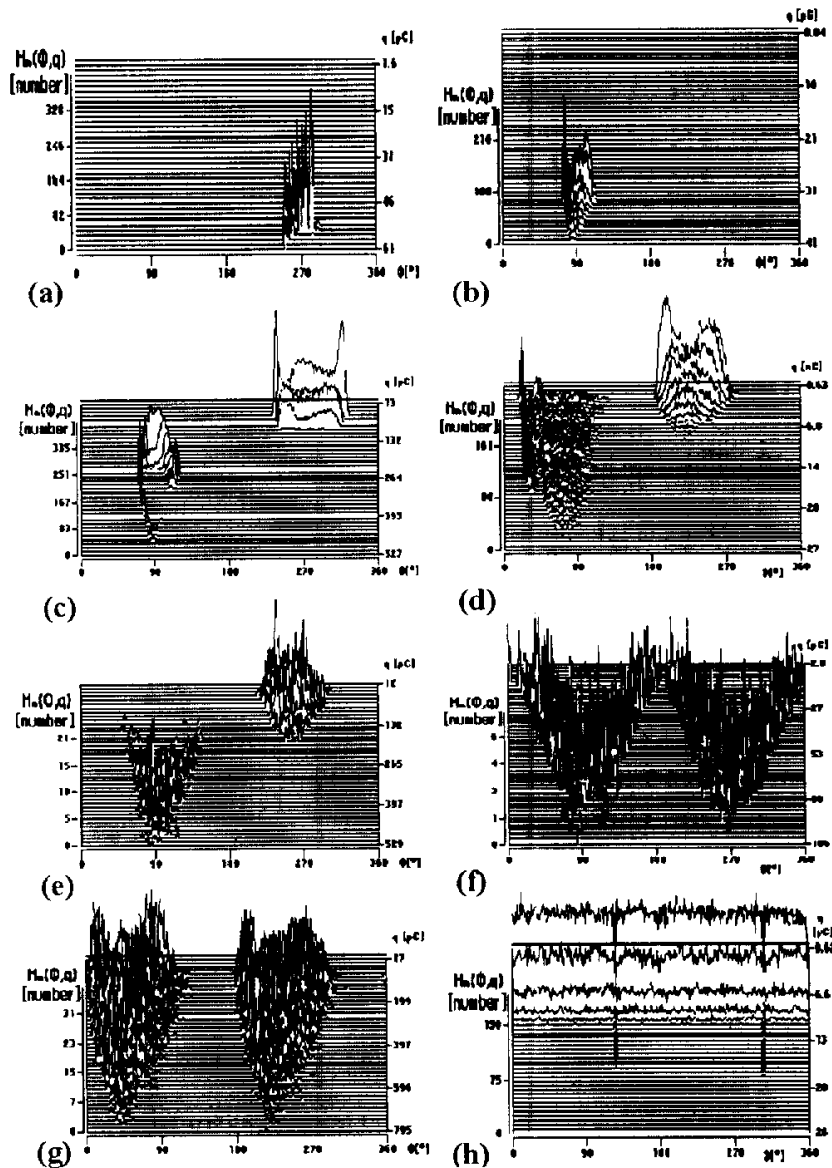

(b)

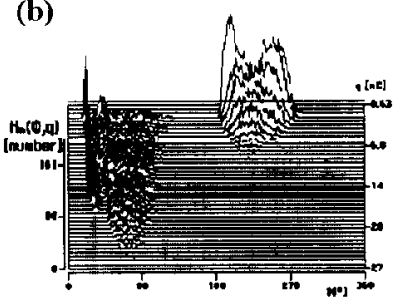

(d)

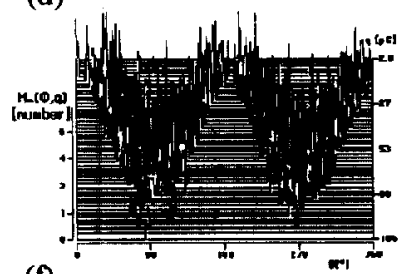

(f)

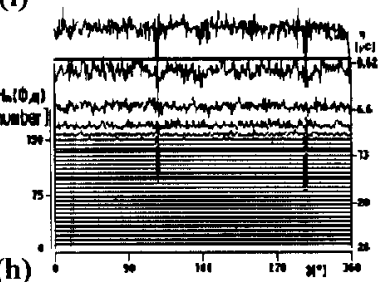

Figure 1 .

3-D discharge patterns of (a) single-point corona in air, at the HV side, (b) single-point corona in air, at the LV side, (c) multiple-point corona in air, at the HV side, (d) surface discharges in air, at the HV side, (e) single-point corona in oil, at the HV side, (f) air bubbles in oil, (g) dielectric bounded cavity, (h) background noise.

windows (typically 2000) and sorts discharges according to their phase of occurrence and discharge magnitude. The discharges are then shown in well-known form of 3D patterns, see Figure 1. Patterns measured due to the following configurations were used:

1. single-point corona in air, at the $\mathrm{HV}$ and the low voltage (LV) side, Figure $1(\mathrm{a})$ and (b),

2. multiple-point corona in air, at the HV side, Figure 1(c),

3. surface discharges in air, at the HV side (a rod-toplane configuration was used), Figure 1(d),

4. single-point corona in oil, at the HV side, Figure 1(e),

5. air bubbles in oil, Figure 1(f),

6. dielectric bounded cavity, diameter 5 to $9 \mathrm{~mm}$, height 0.4 to $0.5 \mathrm{~mm}$, Figure $1(\mathrm{~g})$,

7. background noise, Figure $1(\mathrm{~h})$.

Discharges were measured throughout $2 \mathrm{~min}$ at voltage levels $50 \%$ above the discharge inception. Exceptions were corona discharges (measured at 10 to $60 \%$ above discharge inception) and patterns of background noise. At least six patterns per case were measured.

Some typical features of the discharge patterns should not remain unnoticed $[1,12,20]$. For example, when discharges occur between dielectric surfaces, patterns with approximately equal discharge magnitude in both half cycles of the test voltage are observed, see patterns of dielectric bounded cavity in Figure $1(\mathrm{~g})$ and air bubbles in oil in Figure 1(f). When a metal electrode is involved in a discharge process, discharges with unequal magnitude in the positive and in the negative half cycle of the test voltage are observed, see patterns of surface discharges in air in Figure 1(d) and corona in oil in Figure 1(e). For a single-point corona, at a particular voltage, discharges occur only in one half cycle of the test voltage, see Figure 1(a) and Figure 1(b). Patterns of background noise also include disturbance pulses occurring at constant phase angles.

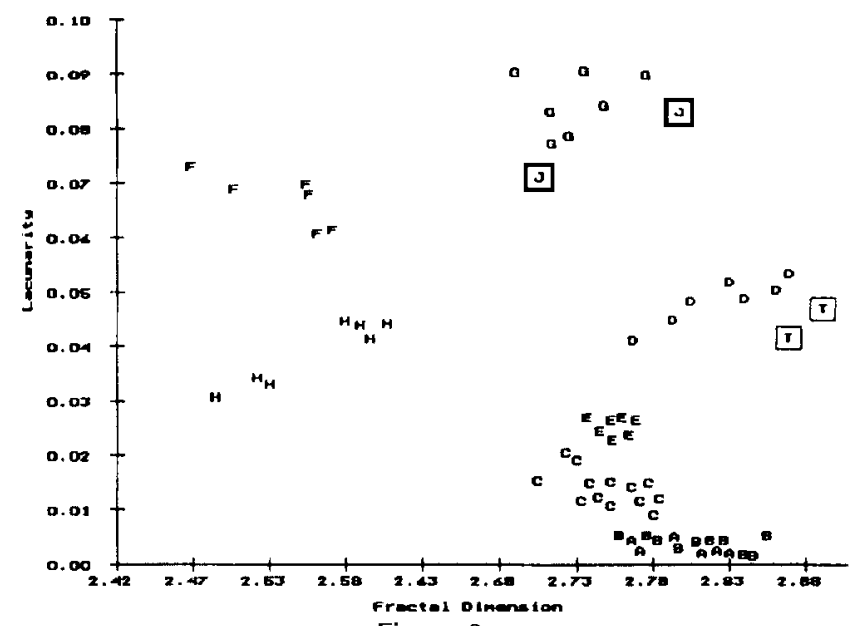

Figure 2.

Scatter plot of 3-D discharge patterns shown in Figure 1 on the fractal feature plane. Each letter represents a single $3-D$ discharge pattern. A: single-point corona in air, at the HV side, B: single-point corona in air, at the LV side, C: multiple-point corona in air, at the HV side, $D$ : surface discharges in air, at the $\mathrm{HV}$ side, $\mathrm{E}$ : single-point corona in oil, at the $\mathrm{HV}$ side, $\mathrm{F}$ : air bubbles in oil, G: dielectric bounded cavity, $\mathrm{H}$ : background noise, $\mathrm{J}$ : discharges in a $17 \mathrm{kV}$ cable joint, $\mathrm{T}$ : discharges in a $17 \mathrm{kV}$ cable termination.

The fractal dimension and lacunarity were calculated for the patterns above. Figure 2 shows the resulting scatter plot of the data. Each letter represents a single 3-D pattern. Several comments have to be made.

Fractal features could not distinguish between patterns of single-point corona in air on the $\mathrm{HV}$ and the $\mathrm{LV}$ side. This was expected because no matter what the position 
of corona 'hill' (see Figure 1), is either around the positive or the negative peak of the test voltage, the surface roughness of the 'hill' (characterized by the fractal dimension) and its denseness (described by lacunarity) is nearly the same. If it is required to recognize between patterns occurring at the HV or LV side, then the phase information on the occurrence of $\mathrm{PD}[12,13,19]$ also have to be included in some way in a recognition system, in addition to the fractal dimension and lacunarity. All other patterns can be distinguished clearly.

By extracting fractal features from 3-D patterns, the absolute quantities such as the discharge magnitude and pulse count rate, are lost. If this type of information is needed, the quantities have to be traced back in the 3-D patterns.

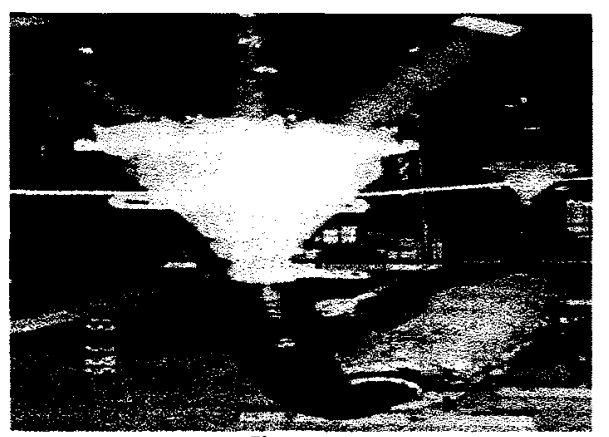

Figure 3.

A $17 \mathrm{kV}$ three-phase cable joint (the iron mass in the lower right part of the Figure) with a triangular cable terminal.

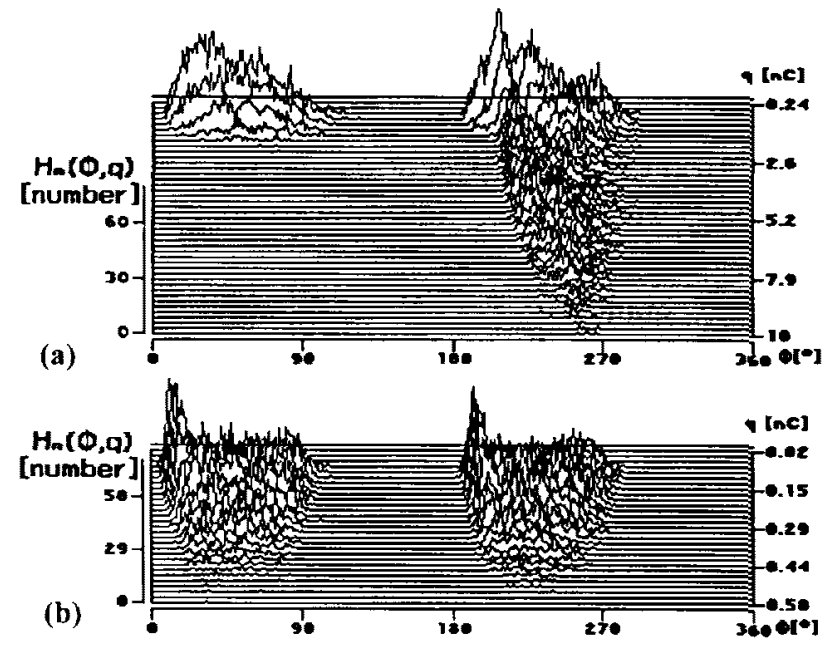

Figure 4.

3-D discharge patterns measured in a $17 \mathrm{kV}$ three-phase (a) cable terminal, (b) cable joint.

In the second test for discrimination in fractal features, discharge patterns arising from a $17 \mathrm{kV}$ three-phase cable joint, were measured (Figure 3). The cable joint has been in service for more than 20 years. The measurements were carried out with one phase energized and two other phases grounded. Two types of discharges were registered: discharges from a cable terminal, see Figure 4(a), and discharges from the cable joint, see Figure 4(b). Discharges from the cable terminal had the discharge magnitude of $\sim 20 \mathrm{nC}$ with much larger discharges in the negative half of the test voltage. The discharges were located by an acoustical probe on the surface of the cable terminal. The pattern highly resembles surface discharges, compare Figures 1(d) and 4(a) (except for the polarity effect which has been discussed above). Also in the fractal feature space the pattern was close to surface discharges (Figure 2), where two measurements are shown.

After repair of the cable terminal, discharges originating from the cable joint were measured. In this case the maximum discharge magnitude was $<500 \mathrm{pC}$ and discharges with approximately equal magnitude occurred in both half cycles of the test voltage. The discharge pattern resembled that of a dielectric bounded cavity, compare Figures $1(\mathrm{~g})$ and $4(\mathrm{~b})$. Also in the fractal feature space the patterns were close to the dielectric bounded cavity (Figure 2), where two measurements are shown.

From the measurements on a $17 \mathrm{kV}$ cable joint follows that even simple artificial models of discharges can provide sufficient information on the origin of discharges in actual HV equipment.

From the results shown in Figure 2 it can be seen that a quite satisfactory discrimination of PD patterns was achieved. The fractal features, namely fractal dimension and lacunarity can perhaps be used in combination with some other features, e.g. statistical parameters [11-13, 19], and classified by well-established pattern recognition methods, e.g. the centour score $[13,21]$, to build a robust $\mathrm{PD}$ recognition system.

\section{CONCLUSIONS}

$\mathrm{T}^{\mathrm{N}}$ this work the use of fractal features for recognition lof 3-D PD patterns was investigated. Two fractal features, the fractal dimension and lacunarity, showed satisfactory discriminating abilities. The fractal features were able to distinguish among a number of patterns. 3-D patterns arising from corona at the $\mathrm{HV}$ and the LV side were recognized as one group. This implies that the phase angle information in addition to two fractal features has to be explicitly provided to make such a discrimination possible. The obtained results are encouraging and the use of the fractal features appears to be a plausible way for $P D$ recognition. The usefulness of the fractal features for discharge recognition should be investigated further. Particularly, recognition of discharges in actual HV components such as generators and transformers and recog- 
nition of multiple PD sources are subjects for future research.

\section{REFERENCES}

[1] F. H. Kreuger, Discharge Detection in High Voltage Equipment, Temple Press, 1964, Butterworths, 1989.

[2] CIGRE Working Group 21.03, "Recognition of Discharges", Electra, No. 11, pp. 61-98, 1969.

[3] J. D. Gassaway, P. B. Jacob, C. A. Vassiliadis, P. H. Reynolds, "Computer-aided Partial Discharge Measurement and Recognition", 5th Int. Conf. on High Voltage Engineering, Braunschweig, Germany, Paper 41.03, 1987.

[4] R. E. Wootton, "Computer Assistance for the Performance and Interpretation of High Voltage ac Discharge Tests", 5th Int. Conf. on HV Engineering, Braunschweig, Germany, Paper 41.12, 1987.

[5] H. G. Kranz and R. Krump, "Partial Discharge Diagnosis Using Statistical Optimization on a PCbased System", IEEE Trans. on Electrical Insulation, Vol.27, pp. 93-98, 1992.

[6] L. Satish and B. I. Gururaj, "Use of Hidden Markov Models for Partial Discharge Pattern Classification", IEEE Trans. on Electrical Insulation, Vol. 28, pp. 172-182, 1993.

[7] H. Suzuki and T. Endoh, "Pattern Recognition of Partial Discharge in a XLPE Cables Using a Neural Network", IEEE Trans. on Electrical Insulation, Vol. 27, pp. 543-549, 1992.

[8] N. Hozumi, T. Okamoto and T. Imajo, "Discrimination of Partial Discharge Patterns Using a Neural Network", IEEE Trans. on Electrical Insulation, Vol. 27, pp. 550-556, 1992.

[9] E. Gulski and A. Krivda, "Neural Networks as a Tool for Recognition of Partial Discharges", IEEE Trans. on Electrical Insulation, Vol. 28, pp. 9841001, 1993.

[10] L. Satish and W. S. Zaengl, "Artificial Neural Networks for Recognition of 3-D Partial Discharge Patterns", IEEE Trans. on Dielectrics and Electrical Insulation, Vol. 1, pp. 265-275, 1994.
[11] T. Okamoto and T. Tanaka, "Novel Partial Discharge Measurement Computer-aided Measurement Systems", IEEE Trans. on Electrical Insulation, Vol. 21, pp. 1015-1019, 1986.

[12] E. Gulski, Computer-Aided Recognition of Partial Discharges Using Statistical Tools, Delft University Press, Delft, 1991.

[13] F. H. Kreuger, E. Gulski and A. Krivda, "Classification of Partial Discharges", IEEE Trans. on Electrical Insulation, Vol. 28, pp. 917-931, 1993.

[14] L. Satish and W. S. Zaengl, "Can Fractal Features be used for Recognizing 3-D Partial Discharge Patterns?", IEEE Trans. on Dielectrics and Electrical Insulation, Vol. 2, pp. 352-359, 1995.

[15] B. B. Mandelbrot, The Fractal Geometry of Nature, Freeman, 1983.

[16] J. M. Keller, S. Chen and R. M. Crownover, "Texture Description and Segmentation through Fractal Geometry", Computer Vision, Graphics, and Image Processing, Vol. 45, pp. 150-166, 1989.

[17] S. Chen, J. M. Keller and R. M. Crownover, "On the Calculation of Fractal features from Images", IEEE Trans. on Pattern Analysis and Machine Intelligence, Vol. 15, pp. 1087-1090, 1993.

[18] A. P. Pentland, "Fractal-based Description of Natural Scenes", IEEE Trans. on Pattern Analysis and Machine Intelligence, Vol. 6, pp. 661-764, 1984.

[19] E. Gulski, P. Seitz, "Computer-aided Registration and Analysis of Partial Discharges in High Voltage Equipment", 8th Int. Conf. on HV Engineering, Yokohama, Japan, Paper 60.04, 1993.

[20] B. Fruth and L. Niemeyer, "The Importance of Statistical Characteristics of Partial Discharge Data", IEEE Trans. on Electrical Insulation, Vol. 27, pp. 60-69, 1992.

[21] R. H. Lindeman, P. F. Merenda and R. Z. Gold, Introduction to Bivariate and Multivariate Analysis, Scott, Foresman and Company, 1980.

${ }^{1}$ Presently with Indian Institute of Science, Department of HV Engineering, Bangalore, India.

Manuscript was received on 4 April 1995, in final form 10 July 1995. 